\title{
ELASTIC PARAMETERS OF INTERMEDIATE SOILS BASED ON BENDER-EXTENDER ELEMENTS PULSE TESTS
}

\author{
Carol Murillo ${ }^{\mathrm{i})}$, Mohammad Sharifipour ${ }^{\mathrm{ii})}$, Bernardo Caicedoiii), \\ Luc ThOREL ${ }^{\text {iv) }}$ and Christophe DANO ${ }^{\text {v) }}$
}

\begin{abstract}
The elastic behaviour of compacted soils subjected to very small strains (smaller than $10^{-5}$ ) is essential, because the serviceability of most geotechnical structures depends on soil elastic properties. Small-strain stiffness of soils was studied in the past years using different experimental devices (mainly resonant columns). However, the results have been relatively inconsistent. The bender elements technique, now extensively used in soil mechanics, offers an efficient non destructive alternative, since it is based on the propagation of shear waves. To enrich the common bender elements testing results providing only shear modulus values, an evolution of the bender elements technique, named bender-extender element's is used in this paper. This device allows the simultaneous measurement of the shear and compression wave velocities. As a result, the two independent elastic constants are measured for the same sample in order to avoid indirect estimations. Also, for unconfined sample's the GrindoSonic test is performed: this test is based on the transient vibrational response of the sample to a slight shock. The present study provides new results about the elastic properties of intermediate unsaturated soils made of mixtures of sand and clay. The results for the elastic properties are presented as a function of the suction level. Finally, a model relating the elastic behaviour of these unsaturated soils is proposed.
\end{abstract}

Key words: deformation, dynamic, laboratory tests, vibration, wave propagation (IGC: D1/D7)

\section{INTRODUCTION}

The identification of elastic parameters is an essential topic in geotechnical engineering. In this paper, particular emphasis is placed on the elastic behaviour of compacted soils subjected to the very small strains (smaller than $10^{-5}$ ) typical in many geotechnical structures, such as roads or railways, embankments and earth structures. Their serviceability is clearly determined by soil elastic properties which depend on the water content and suction level.

Small-strain stiffness of soils has been studied in the past using different experimental devices (mainly resonant columns but also local small strain devices). However, the results have been relatively inconsistent. The bender elements technique now extensively used in soil mechanics (e.g., Viggiani and Atkinson, 1995; Brignoli et al., 1996; Fratta and Santamarina, 1996; Fam and Santamarina, 1997; Kawaguchi et al., 2001; Leong et al., 2005) offers an efficient alternative despite some shortcomings relative to interpretation methods. The most common bender element device was developed by Shirley and Hampton (1977): it allows the propagation of shear waves, with only the shear modulus $G$ directly measurable. An evolution of the bender elements technique, named bender-extender elements, was developed by Lings and Greening (2001). This device allows for the simultaneous measurement of the shear and compression wave velocities. Consequently, two independent elastic constants are determined on the same sample, and indirect estimations can be avoided.

Most of the studies involving bender elements have been performed on purely frictional sands or soft cohesive soils (clays). Few results concern intermediate soils made of a mixture of sand and clay (Rossato et al., 1992; Kimura et al., 1994), which are both cohesive and frictional. The present study provides new results about the elastic properties of intermediate unsaturated soils made of mixtures of sand and clay, identified using the bender-extender elements testing device. More, the experimental investigation has been completed with GrindoSonic pulse tests to evaluate the elastic properties of samples in unconfined conditions and therefore assist the user in the determination of wave travel times by the ben-

Professor, Department of Civil and Agricultural Engineering National University of Colombia, Colombia.

ii) Razi University, formerly at Research Institute in Civil and Mechanical Engineering, Ecole Centrale Nantes, University of Nantes, France.

iii) Department of Civil and Environmental Engineering, University of Los Andes, Colombia (bcaicedo@uniandes.edu.co).

iv) Senior Researcher, LUNAM University, IFSTTAR, Department of Geotechnical Engineering, Environment and Risks, Physical Modelling in Geotechnics Group, France.

v) Associate Professor, Research Institute in Civil and Mechanical Engineering, Ecole Centrale Nantes, University of Nantes, France. The manuscript for this paper was received for review on June 18, 2010; approved on March 8, 2011.

Written discussions on this paper should be submitted before May 1, 2012 to the Japanese Geotechnical Society, 4-38-2, Sengoku, Bunkyo-ku, Tokyo 112-0011, Japan. Upon request the closing date may be extended one month. 
der extender elements technique. The GrindoSonic method, more often employed in concrete characterization, is based on the transient vibrational response of a sample subjected to a slight shock. The new scope of investigation, focusing on intermediate soils also requires some key points related to wave propagation, like the determination of the travel times, near field effects and influence of the shape of signal to be revisited.

The resulting values of the elastic properties of intermediate compacted soils are presented, with the suction level in the soil specimens taken into consideration. Finally, a model describing the elastic behaviour of these unsaturated soils is proposed.

\section{TESTED SOILS}

The tested compacted soils are reconstituted in the laboratory from different mixtures, defined by their weight percentage of Speswhite kaolin (SPW), and Missillac sand (MS). The index properties of the SPW clay are a liquid limit of $55.1 \%$, a plastic limit of $32.3 \%$, and a specific gravity Gs of 2.62, the specific gravity Gs of the sand fraction MS is 2.65. Figure 1 shows the grain size distributions of these soils. Note that the grain size distri-

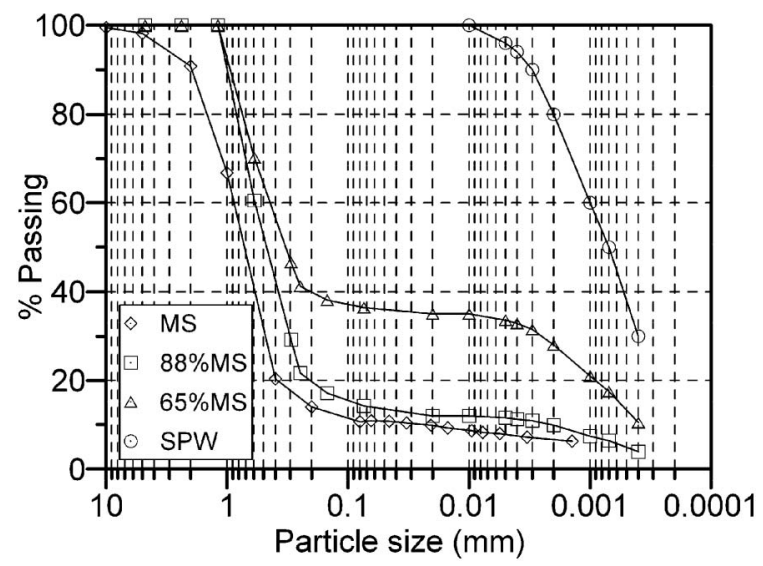

Fig. 1. Particle size distribution for Speswhite Kaolin (SPW or S1), Missilac Sand (MS) and mixtures S2 and S3

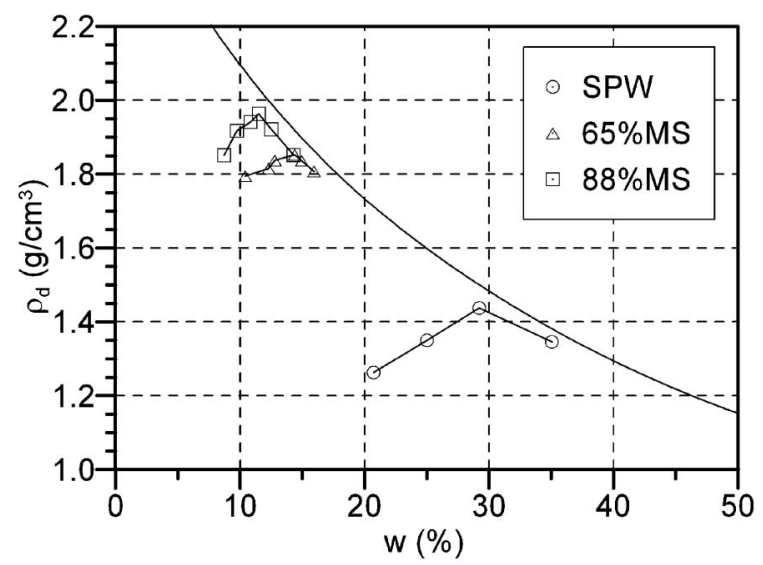

bution for grains smaller than $0.2 \mu \mathrm{m}$ is measured using a laser granulometer according to the ISO 13320-1 standard (1999).

Three different mixtures of soils were studied. These mixtures fall in three different categories of soils according to the French Road Soil Classification System (LCPC, 1992, 2003), which is based mainly on the grain size distribution and on the Methylene blue absorption. In this system, the soils are respectively classified as A3, B6 and B31. According to the AASHTO soils classification system, these soils are ranked as A-7-5, A-1-a, and A-2-7, respectively. In the following paragraphs, the soils used in this study are designated as S1 for A3 or AASHTO A-7-5; S2 for B6 or AASHTO A-1; and S3 for B31 or AASHTO A-2-7. The mass percentage of MS for each of these soils is $0 \%(\mathrm{~S} 1), 65 \%$ (S2) and $88 \%$ (S3); and the Methylene blue absorption values are 1.54, 1.21, and $1.11 \mathrm{~g} / 100 \mathrm{~g}$ for the $\mathrm{S} 1, \mathrm{~S} 2$, and $\mathrm{S} 3$, respectively.

Soil S3, which includes the smallest percentage of kaolin, has the highest dry maximum unit weight measured following the standard Proctor test (Fig. 2) by comparison with S2 and S1. These results agree with those obtained by Boussaid et al. (2003) with intermediate soils made of Fontainebleau sand and SPW.

\section{SAMPLES CHARACTERISTICS}

\section{Reconstitution}

Sand is sifted in different fractions with maximum grain sizes of $1 \mathrm{~mm}, 0.5 \mathrm{~mm}, 0.2 \mathrm{~mm}$ and $80 \mu \mathrm{m}$, respectively. Fractions lower than $1 \mathrm{~mm}$ are then mixed in a 0.14 $\mathrm{m}^{3}$ concrete mixer to reconstitute the material, and avoid segregation. Kaolin is then added and mixed for three minutes to obtain a dry and homogeneous mixture. To obtain S1, S3 and S2 soils, 28\%, 11\% and 13\% of water is added, respectively. The optimum Proctor water contents are $29.2 \%, 11.5 \%$, and $14.4 \%$ respectively.

\section{Compaction}

The mixture is introduced into a $30 \mathrm{~cm}$ large and $40 \mathrm{~cm}$ high cylindrical container in three successive layers of about $10 \mathrm{~cm}$ each. The soil mass is then subjected to a compressive vertical stress $\left(\sigma_{\mathrm{v}}\right)$ using a pressure-controlled hydraulic actuator. The final vertical stress is equal to $2 \mathrm{MPa}$ for $\mathrm{S} 1$ and $2.5 \mathrm{MPa}$ for $\mathrm{S} 2$ and $\mathrm{S} 3$. The static compaction on specimens is applied for 10 minutes on each soil layer. After 10 minutes of compaction, no additional settlement is measured. The obtained density is calculated classically as the ratio of the mass and the volume of the sample. These values allow for a homogeneous material with a dry density close to the maximum Proctor density (Murillo et al., 2009a, 2009b). Four steel cores $(10 \mathrm{~cm}$ in diameter, $20 \mathrm{~cm} \mathrm{long})$ are finally placed on the top surface of the compacted soil. Using a hydraulic actuator, the steel cores are fully driven in the soil mass. Finally, each core sample is taken out from the mould.

Fig. 2. Proctor test results 
Table 1. Soil sample properties

\begin{tabular}{c|c|c|c|c|c|c|c|c}
\hline \multirow{2}{*}{ Soil } & $\begin{array}{c}\phi \\
(\mathrm{cm})\end{array}$ & $\begin{array}{c}h_{\mathrm{i}} \\
(\mathrm{cm})\end{array}$ & $\begin{array}{c}w_{\mathrm{i}} \\
(\%)\end{array}$ & $\begin{array}{c}w_{\mathrm{f}} \\
(\%)\end{array}$ & $\begin{array}{c}\rho_{\mathrm{d}} \\
\left(\mathrm{gr} / \mathrm{cm}^{3}\right)\end{array}$ & $e_{\mathrm{i}}$ & $\begin{array}{c}S_{\mathrm{ri}} \\
(\%)\end{array}$ & $\begin{array}{c}u_{\mathrm{a}}-u_{\mathrm{w}} \\
\mathrm{kPa}\end{array}$ \\
\hline \multirow{2}{*}{$\mathrm{S} 1$} & 9.51 & 7.14 & 27.26 & 28.28 & 1.44 & 0.837 & 90 & \multirow{2}{*}{8000} \\
\cline { 2 - 9 } & 9.53 & 9.65 & 28.14 & 28.32 & 1.46 & 0.815 & 92 & \\
\hline \multirow{2}{*}{$\mathrm{S} 2$} & 9.51 & 6.99 & 10.79 & 11.74 & 1.84 & 0.484 & 63 & 1500 \\
\cline { 2 - 9 } & 9.51 & 9.85 & 15.32 & 15.5 & 1.81 & 0.487 & 85 & 300 \\
\hline \multirow{2}{*}{$\mathrm{S} 3$} & 9.53 & 7.44 & 11.21 & 11.13 & 1.94 & 0.374 & 80 & \multirow{2}{*}{60} \\
\cline { 2 - 8 } & 9.51 & 9.85 & 11.28 & 11.29 & 1.93 & 0.384 & 78 & \\
\hline
\end{tabular}

\section{Soil Samples Properties}

Table 1 summarizes the main characteristics of the samples. The diameter $\phi$ is constant but the samples have been cut at two initial lengths $h_{\mathrm{i}}$ (about 7 and $10 \mathrm{~cm}$ ), for each soil. The initial water content $w_{\mathrm{i}}$ (expected value) is close to the final water content $w_{\mathrm{f}}$ (measured value). The dry density $\rho_{\mathrm{d}}$ and the initial void ratio $e_{\mathrm{i}}$ are similar for each sample of the same compacted soil showing good homogeneity from the compaction procedure. Furthermore, the initial water content (or initial degree of saturation $S_{\mathrm{ri}}$ ) is approximately the same for the samples of each soil, except for S2, in order to examine the effect of the saturation degree. Samples of compacted soils are taken to measure their suction value using a pressure plate cell apparatus for soil S3 and a WP4-T chilled mirror apparatus for soils S1 and S2. The mean suction values of the three different soils are presented in Table 1. The matric suction of the samples cover a broad range from $60 \mathrm{kPa}$ for soil S3 with $88 \%$ sand to $8000 \mathrm{kPa}$ for soil S1 with $100 \%$ of kaolin; soil S2 with $65 \%$ of sand was tested at two water contents: $11 \%$ and $15 \%$, corresponding to $1500 \mathrm{kPa}$ and $300 \mathrm{kPa}$ matric suction, respectively.

\section{EXPERIMENTAL DEVICES}

Two non-destructive methods were used to indirectly identify the elastic properties of the tested soils in the small strain domain: the GrindoSonic method, for unconfined samples and the bender-extender elements method for confined samples.

\section{GrindoSonic}

For unconfined samples, the shear $\left(V_{\mathrm{S}}\right)$ and compression $\left(V_{\mathrm{P}}\right)$ waves velocities were deduced from the fundamental resonant frequency of S1 and S2 samples using a non-destructive device, called GrindoSonic (Allison, 1988). The GrindoSonic device is used to generate and detect a short transient vibration propagating through a cohesive sample resulting from a mechanical disturbance caused by a light mechanical impulse, generated by a light plastic hammer blow. Two pulse modes (torsion and bending) are required to measure the elastic parameters: they are obtained by varying the positions of both the hammer stroke and the detector.

The wave propagation is recorded using a piezoelectric detector in contact with the sample and then converted
Table 2. GrindoSonic test results

\begin{tabular}{c|c|c|c|c|c|c|c}
\hline Soil & $\begin{array}{c}\text { Bending } \\
\text { frequency } \\
(\mathrm{Hz})\end{array}$ & $\begin{array}{c}\text { Torsion } \\
\text { frequency } \\
(\mathrm{Hz})\end{array}$ & $\begin{array}{c}V_{\mathrm{s}} \\
(\mathrm{m} / \mathrm{s})\end{array}$ & $\begin{array}{c}V_{\mathrm{p}} \\
(\mathrm{m} / \mathrm{s})\end{array}$ & $\begin{array}{c}G \\
(\mathrm{MPa})\end{array}$ & $\begin{array}{c}E \\
(\mathrm{MPa})\end{array}$ & $v$ \\
\hline $\mathrm{S} 1$ & 740 & 728 & 292 & 623 & 157 & 465 & 0.45 \\
\hline $\mathrm{S} 2$ & 986 & 1020 & 404 & 757 & 340 & 880 & 0.3 \\
\hline
\end{tabular}

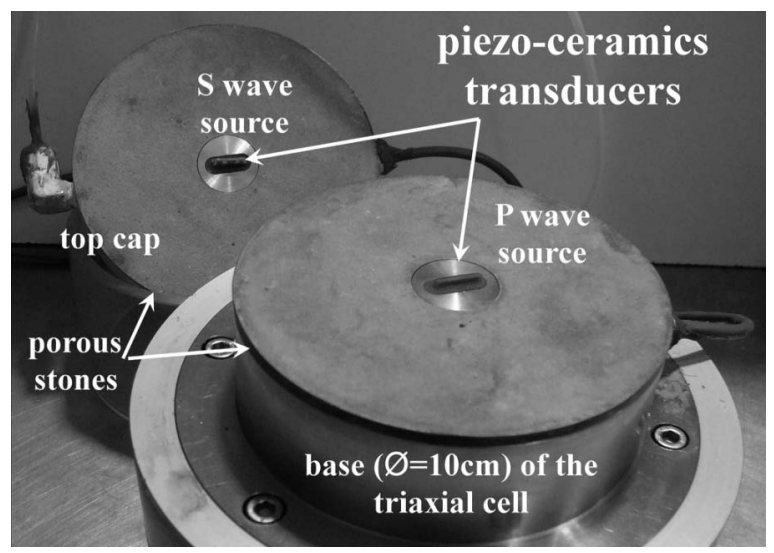

Fig. 3. Bender extender elements

into an electronic signal. The fundamental resonant frequency is automatically determined from the analysis of the signal. At least five consistent measurements are required to consider the statistical reliability of the result. A mathematical application (Spinner and Tefft, 1961) is then used to identify the two independent parameters (Young's modulus $E$ and shear modulus $G$ ) describing the isotropic-linear-elastic materials from the geometrical and physical data of the samples as well as from their fundamental frequencies.

The results (Table 2) provide a rough estimate of the elastic properties of unconfined samples which is useful for comparison with bender-extender measurements at zero confining pressure in the triaxial cell.

\section{Bender-Extender Elements}

A couple of piezo-ceramics transducers, called benderextender elements (Fig. 3), is used to measure both compression ( $\mathrm{P}$-waves) and shear (S-waves) waves. This device is extensively described in Lings and Greening (2001). The bender-extender elements withstand a relatively large range of confining pressures, and they can be excited with different input signal frequencies and shapes.

The piezo-ceramics transducers are embedded into the top cap and the base of a triaxial compression test apparatus. The upper element is excited by an electrical pulse which initiates a shear wave through the specimen. On the other hand, a compression wave is generated upwards by the lower element. When each wave reaches the opposite element, the mechanical movement is then converted into an electric signal. Both the input and output signals are recorded.

Each sample is pressed on the lower element to main- 
tain perfect contact between the tested material and the transducer. The upper element is also pressed onto the sample. As a result, both elements penetrate into the sample over a depth of $2.5 \mathrm{~mm}$. Special attention is also given to the alignment and the position of the two elements for polarization and signals quality reasons. The cell pressure is controlled with a $2 \mathrm{MPa}$ hydraulic actuator, which has a total volume of $200 \mathrm{~cm}^{3}$.

During tests, the shape (sine, square) and the frequency $(5,6.7,8.3$, and $10 \mathrm{kHz})$ of the excitation signal are imposed by the user through the software interface. The sampling rate is $10^{5}$ samples per second $(100 \mathrm{kHz})$, and the amplitude of the signal is \pm 5 volts. Tests were carried out on samples of $10 \mathrm{~cm}$ in diameter and 7 or $10 \mathrm{~cm}$ in height (Table 1). Records of wave propagation were performed for different confining pressures, varying from 0 (before filling the cell with water) to $500 \mathrm{kPa}$ along isotropic loading stress paths. The samples are protected from the confining fluid by a thin $0.5 \mathrm{~mm}$ thick latex membrane, adding a confining stress of $0.3 \mathrm{kPa}$.

Variations of the sample height under pressure are assessed by an external gauge. Measurement errors are unavoidable because of the bedding effect and the compliance of the system (Scholey et al., 1995). The errors, however, remain small because of the specimen stiffness (approximately $200 \mathrm{MN} / \mathrm{m}^{2}$ for the mean value of the shear modulus). The size (diameter and height) and the mass of the specimens are initially carefully measured.

Assuming isotropy and homogeneity, the elastic parameters characterizing the linear elastic behavior $(E$, $G)$, and Poisson ratio $v$ are related to the wave velocities in the framework of the mechanics of continuous media (e.g. Foti, 2000):

$$
\begin{aligned}
& G=\rho \cdot V_{\mathrm{s}}^{2} \\
& E=\frac{\rho V_{\mathrm{s}}^{2}\left(3 V_{\mathrm{p}}^{2}-4 V_{\mathrm{s}}^{2}\right)}{V_{\mathrm{p}}^{2}-V_{\mathrm{s}}^{2}} \\
& \nu=\frac{V_{\mathrm{p}}^{2}-2 V_{\mathrm{s}}^{2}}{2\left(V_{\mathrm{p}}^{2}-V_{\mathrm{s}}^{2}\right)}
\end{aligned}
$$

where $V_{\mathrm{s}}$ is the shear wave velocity, $V_{\mathrm{P}}$ is the compression wave velocity, and $\rho$ is the density of the soil.

The velocity of the waves is given by:

$$
V=\frac{L}{T}
$$

where $L$ is the effective tip-to-tip distance between the two bender-extender elements, corrected to take into account the shortening of the sample during the test, in compliance with the recommendations by Viggiani and Atkinson (1995), Jovičić et al. (1996), and Brignoli et al. (1996) and $T$ is the wave travel time relative to the compression wave, $T_{\mathrm{p}}$, or the shear wave, $T_{\mathrm{s}}$. Travel times result from the analysis of the electric signals recorded during the tests.

The identification of $T_{\mathrm{P}}$ is relatively easy since it corresponds to the time interval between the input signal initial point and the output signal first deviation, usually clear enough, even if the amplitude of the $\mathrm{P}$-wave is ten

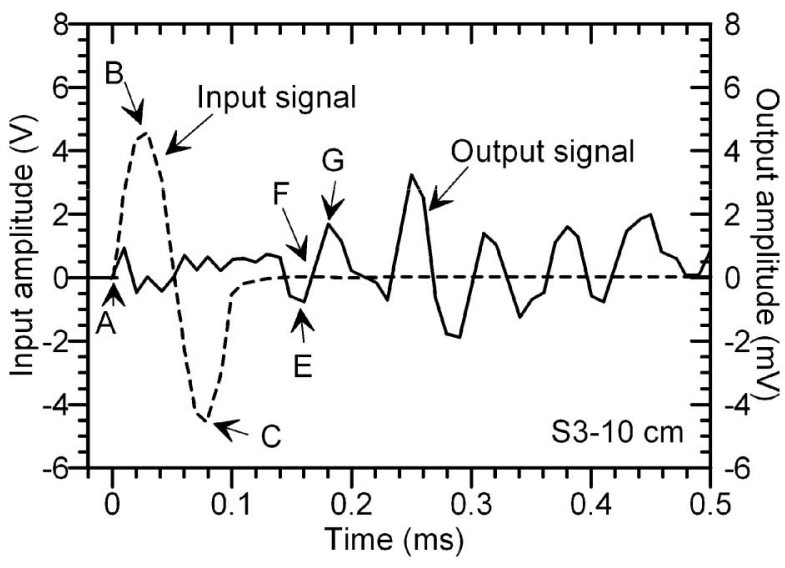

Fig. 4. Typical input and output signals of shear waves-characteristic points

times lower than the amplitude of the shear wave.

The estimation of $T_{\mathrm{s}}$ by a visual inspection of the signals has been debated since the mid-90's (Jovičić et al., 1996). However, this evaluation is somewhat difficult due to near-field effects. The interpretation methods reported in the literature are summarized in Table 3. The first arrival analysis is recommended for identification of wave velocities in rock samples (ASTM D 2845). Other characteristic points can be also selected in both input and output signals to determine travel time. In Fig. 4 points A, B and $C$ are the first deflection, the positive peak and the negative peak of the input signal, respectively.

Different points can be identified on the output signal (Fig. 4): point E corresponds to the first arrival inversion, point $F$ to the first zero value observed immediately after point $\mathrm{E}$, and point $\mathrm{G}$ is the first peak. The identification of these points is possible while the noise level on the output signal is less than approximately $10 \%$ of the maximum amplitude.

Different methods can be used to identify the travel time of the shear wave $T_{\mathrm{s}}$ : (e.g., peak-to-peak time B-G method, cross-correlation method).

According to Viggiani and Atkinson (1995), Lohani et al. (1999) and Kawaguchi et al. (2001), the travel time corresponding to the peak-to peak distance between the input and output signals might be globally wrong except for high frequency input signals. The difficulty to establish the peak in the output signal may generate errors mainly for square waves where no clear peak appears, particularly at low frequencies, for which the wave period is large.

The cross-correlation method (Mancuso et al., 1989; Viggiani and Atkinson, 1995; Mohsin and Airey, 2003) is a mathematical tool (Eq. (5)) that provides a reliable indication on the similarity between the signals and on the degree of distortion. This method allows assessing the travel time of both shear and compression waves.

The cross-correlation function (Eq. (5)) combines the input signal $\left(S_{1}\right)$ with an output signal $\left(S_{2}\right)$ with a time $t$ as a delay gap. The travel time $T_{\mathrm{cc} 1}$ or $T_{\mathrm{cc} 2}$ corresponds to the time delays that give the cross-correlation its first and sec- 


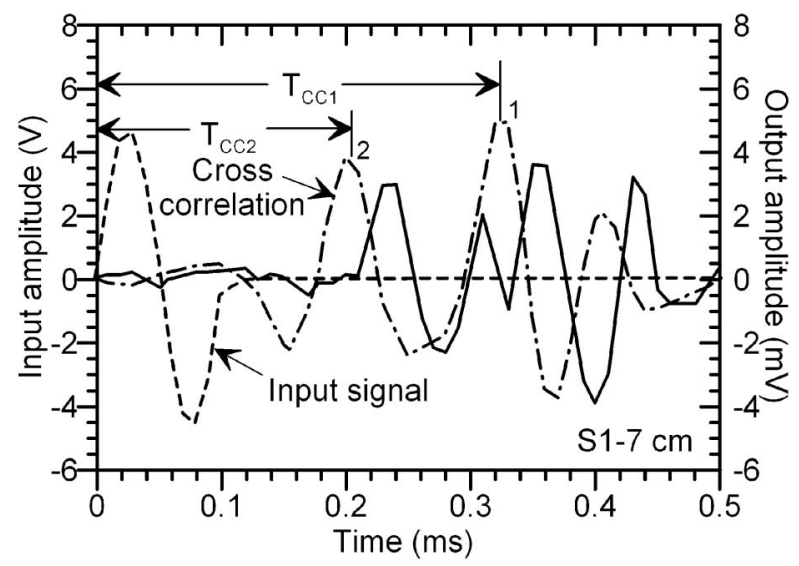

Fig. 5. Cross correlation method

Table 3. Interpretation methods reported in the literature for the determination of the shear wave travel time

\begin{tabular}{l|c|l|l}
\hline \multicolumn{1}{c|}{ Method } & Notation & \multicolumn{1}{|c}{ Principle } & \multicolumn{1}{c}{ Reference } \\
\hline $\begin{array}{l}\text { Inversion } \\
\text { (AE) }\end{array}$ & Inv & $\begin{array}{l}\text { First inversion of the } \\
\text { output signal }\end{array}$ & $\begin{array}{l}\text { Dyvik and Madshus } \\
(1985)\end{array}$ \\
\hline $\begin{array}{l}\text { First arrival } \\
\text { (AF) }\end{array}$ & First & $\begin{array}{l}\text { First zero value } \\
\text { immediately after } \\
\text { inversion of signal }\end{array}$ & Jovičić et al. (1996) \\
\hline $\begin{array}{l}\text { Peak to peak } \\
\text { (BG) }\end{array}$ & P-P & $\begin{array}{l}\text { Difference between } \\
\text { peaks for output and } \\
\text { input signal }\end{array}$ & $\begin{array}{l}\text { Viggiani and Atkinson } \\
\text { (1995) }\end{array}$ \\
\hline & CC1 & $\begin{array}{l}\text { Maximum value of } \\
\text { the cross-correlation }\end{array}$ & $\begin{array}{l}\text { Mancuso et al. (1989), } \\
\text { Viggiani and Atkinson } \\
(1995), \text { Mohsin and Airey } \\
\text { (2003) }\end{array}$ \\
\cline { 2 - 4 } $\begin{array}{l}\text { Cross- } \\
\text { correlation }\end{array}$ & CC2 & $\begin{array}{l}\text { Second maximum } \\
\text { value of the cross- } \\
\text { correlation }\end{array}$ & $\begin{array}{l}\text { Boulanger et al. (1998), } \\
\text { Sharifipour et al. (2004) }\end{array}$ \\
\hline
\end{tabular}

ond maximum values (Fig. 5).

$$
c c_{\mathrm{s}_{1} \mathrm{~S}_{2}}(t)=\lim _{\mathrm{T} \rightarrow \infty} \frac{1}{T_{\mathrm{r}}} \int_{T_{\mathrm{r}}} S_{1}(T+t) S_{2}(T) d T
$$

The GrindoSonic technique, which is rapid, non-destructive and reliable, can be easily carried out on cohesive and frictional unconfined samples to estimate the elastic properties, and consequently the wave velocities in the tested soil. These measurements provide a helpful indication to evaluate the reliability of each interpretation method applied to the bender-extender technique.

\section{INFLUENCE OF THE DIFFERENT TEST CONDITIONS ON THE SHEAR WAVE VELOCITY}

A total of 768 wave velocity measurements have been carried out: 6 samples, 16 stages of confining pressures (between 0 and $500 \mathrm{kPa}$ ), 4 input frequencies $(5,6.7,8.3$ and $10 \mathrm{kHz}$ ), and 2 signal shapes (sine or square).

\section{Near-Field Effects}

Near-field effects appear as a result of a compression

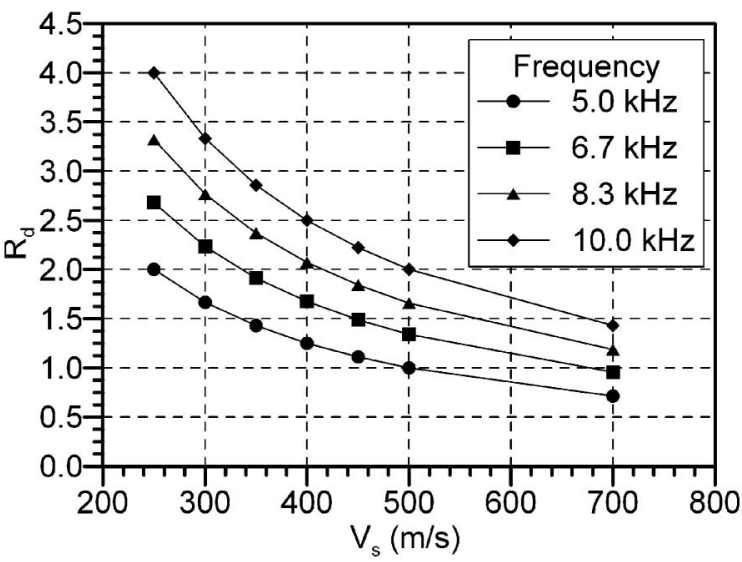

Fig. 6. Effect of $V_{\mathrm{S}}$ on $R_{\mathrm{d}}$ for $10 \mathrm{~cm}$ high samples

wave that propagates through the sample and mask the arrival of the driven shear wave. This phenomenon occurs when the ratio $R_{\mathrm{d}}$ between the length of the sample to the signal wave length is smaller than four (SanchezSalinero et al., 1986; Jovičić et al., 1996; Brignoli et al., 1996; Lo Presti et al., 1995). In our case, bender-extender elements provide a direct measurement of the $\mathrm{P}$-wave velocity: therefore, the outset of near-field effect influence can be more easily identified in the shear wave output signals.

Initial tests were carried out on $20 \mathrm{~cm}$ high samples. However, after several attempts no clear response could be achieved for these specimens due to the weak energy of the wave which was limited to $10 \mathrm{kHz}$ by the technology of the device. Due to this limitation, the tests were performed on smaller samples ( $7 \mathrm{~cm}$ and $10 \mathrm{~cm}$ high) even though near-field effect is enhanced.

The near-field effects are therefore systematically present during all the tests since the value of $R_{\mathrm{d}}$ is between 0.5 and 3.4 for $7 \mathrm{~cm}$ high samples, and 0.7 to 4 for $10 \mathrm{~cm}$ high samples. It is important to note that the $R_{\mathrm{d}}$ value is affected by the frequency of the input signal and the shear wave velocity, as shown in Fig. 6 for $10 \mathrm{~cm}$ high samples.

\section{Influence of the Signal Shape}

There is no significant difference between the travels times obtained when the sample is excited with either pseudo sine or square waves (Fig. 7). However, each type of signal has advantages and disadvantages: (i) the identification of the peak in the sine signal is easier and for this reason, the results of the sine signals, are less scattered than those obtained with the square signals; (ii) for square wave excitations, the quality of the output signals satisfies all confining pressures and excitation frequencies, whereas the pseudo-sine wave excitation is effective when the excitation frequency is greater than $5 \mathrm{kHz}$ only. This is probably due to the fact that the power spectrum for sine pulses is narrower than the power spectrum for square signals.

\section{Influence of the Frequency}

The large frequency spectrum of the output signals re- 
quires a more extensive analysis. Moreover, for granular and unsaturated soils, dispersion and attenuation phenomena appear. A frequency analysis to identify a group velocity and the phase velocities could integrate these phenomena whereas the basic analysis presented here only treats the faster wave between a source and a receiver. All the interferences, except for the near-field effects, are therefore ignored.

The excitation frequency has an effect on the $R_{\mathrm{d}}$ ratio and therefore affects the shape of the output signal. The selection of a suitable frequency for the input pulse has received considerable attention in the literature (see for instance Arulnathan et al., 1998). Near-field effects may vanish, whereas the input frequency increases but interactions between the grains and wave (multiple scattering effect) may happen as a result. The range of frequencies used here is an acceptable compromise between these two antagonistic phenomena.

Consistent shear wave velocities deduced from the travel times $T_{\text {inv }}$ and $T_{\text {First }}$ (corresponding to the inversion and first arrival methods, described in Table 3) are obtained for all the specimens at all the excitation frequen-

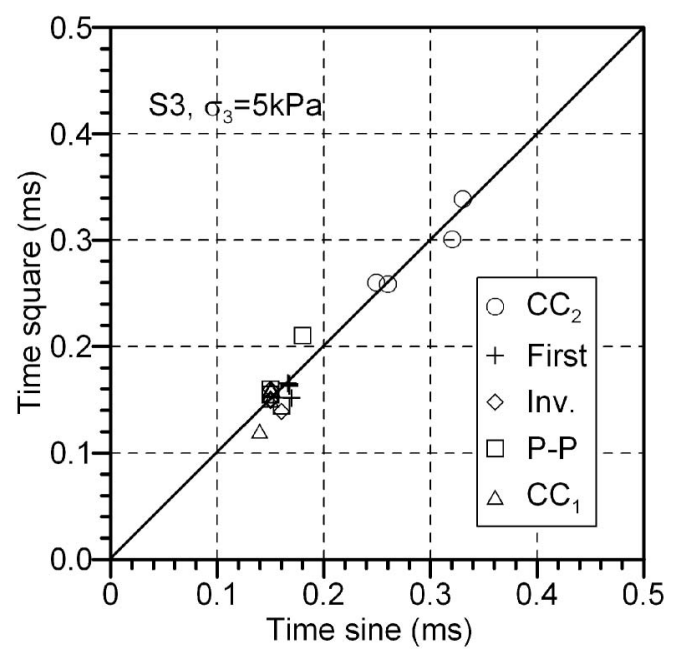

Fig. 7. Time for different shape of the input signals (sine vs square) for $\mathrm{S3}$ soil and $\sigma_{3}=5 \mathrm{kPa}$

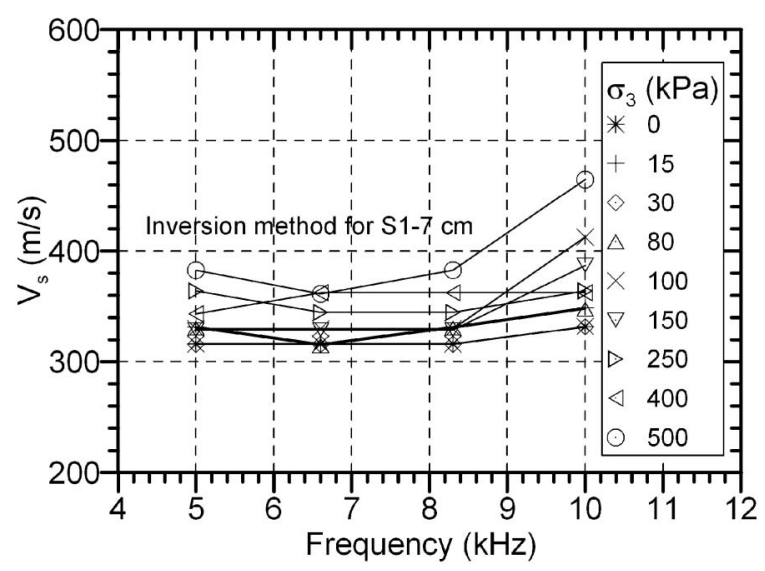

Fig. 8. Shear wave velocities for inversion method (S1) cies and confining pressures used in the testing program (an example is given in Fig. 8 for the inversion method). These two travel times were more specifically chosen because of the experience noted in the literature, even though that question is still open for discussion. There is still no objective argument in favour of either time interval A-E or A-F.

\section{RESULTS AND DISCUSSION}

A commercial signal processing software is used to display and process the input and output signal as well as the cross-correlations between the signals.

Figures 9 to 14 summarize the velocities assessed using the methods previously described, versus confining pressures at $10 \mathrm{kHz}$ for soils S1, S2 and S3 and for samples of $7 \mathrm{~cm}$ and $10 \mathrm{~cm}$ length. Bender-extender element tests are performed up to $500 \mathrm{kPa}$. This stress level includes the range of interest of the subgrade layers of pavements.

Regarding the effect of the interpretation method, Figs. 9 to 14 show similar values of shear wave velocity when

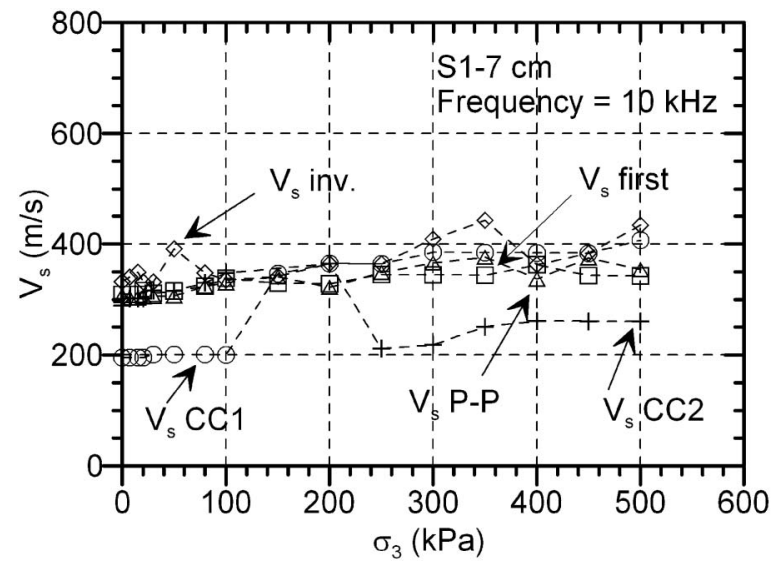

Fig. 9. Comparison of the different interpretation methods for the computation of shear waves velocities $(\mathrm{S} 1-7 \mathrm{~cm}$ sample, $f=10$ kHz, $\left.w=28 \%, u_{\mathrm{a}}-u_{\mathrm{w}}=8000 \mathrm{kPa}\right)$

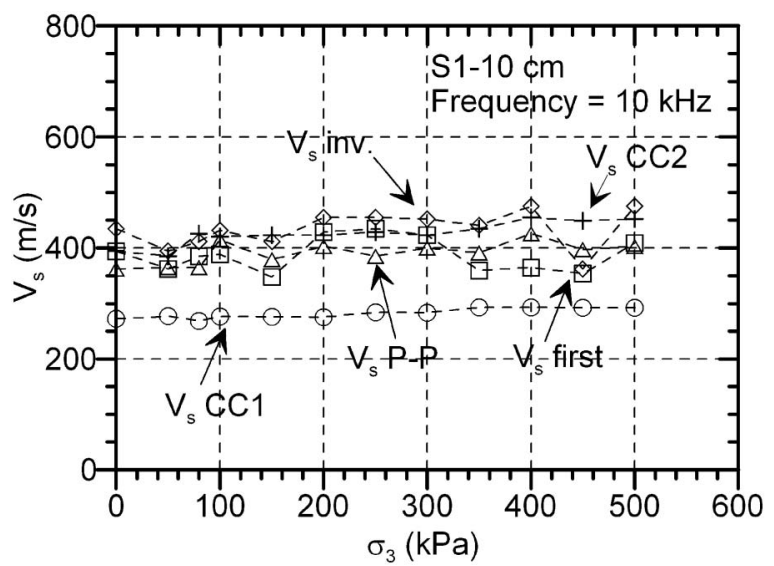

Fig. 10. Comparison of the different interpretation methods for the computation of shear waves velocities $(\mathbf{S 1 - 1 0} \mathrm{cm}$ sample, $f=10$ kHz, $\left.w=28 \%, u_{\mathrm{a}}-u_{\mathrm{w}}=8000 \mathrm{kPa}\right)$ 


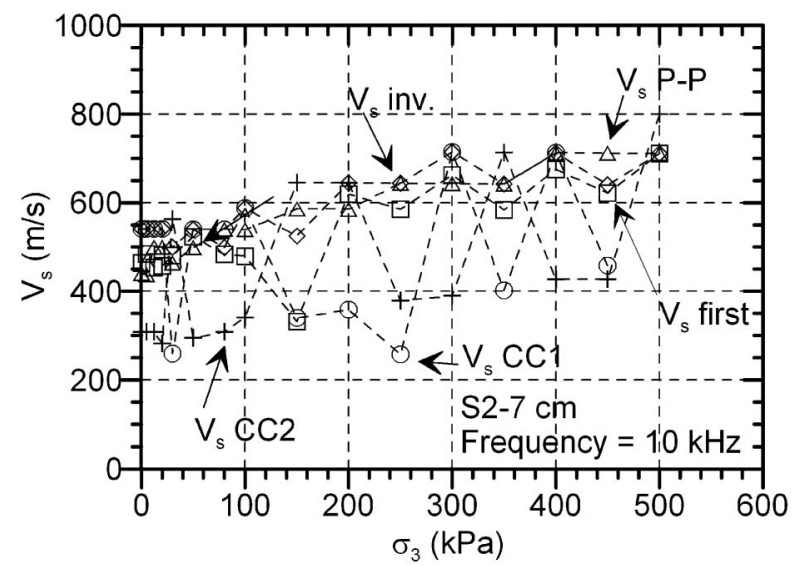

Fig. 11. Comparison of the different interpretation methods for the computation of shear waves velocities $(S 2-7 \mathrm{~cm}$ sample, $f=10$ $\left.\mathrm{kHz}, w=11 \%, u_{\mathrm{a}}-u_{\mathrm{w}}=1500 \mathrm{kPa}\right)$

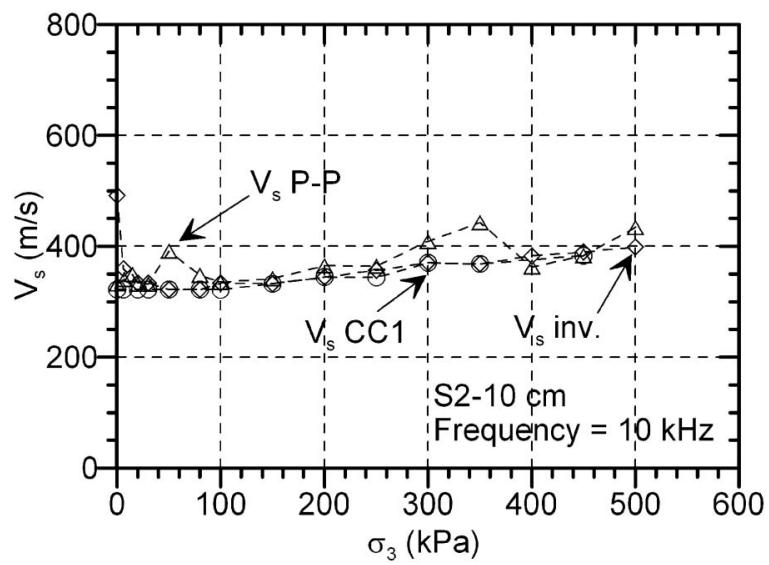

Fig. 12. Comparison of the different interpretation methods for the computation of shear waves velocities ( $(\mathrm{S} 2-10 \mathrm{~cm}$ sample, $f=10$ $\left.\mathbf{k H z}, w=15 \%, u_{\mathrm{a}}-u_{\mathrm{w}}=300 \mathrm{kPa}\right)$

the first arrival and peak-to-peak methods are used; however, no clear criteria can be estimated from the cross-correlation method. This discrepancy appears because cross-correlation results depend mainly on the position of the maximum amplitude in the output signals; this means that if the first peak is not the maximum amplitude, $T_{\text {cc }}$ is shifted to the right, towards higher values of time.

Without considering the cross correlation method, it is difficult to state which method among inversions and first deflections is the most appropriate. The trends of evolution are similar for both methods, but the scattering of shear wave velocities depending on the interpretation methods is approximately $\pm 50 \mathrm{~m} / \mathrm{s}$. For this reason, further analyses presented in this paper are based on the average value. By doing that, uncertainty is introduced regarding the precise value of $V_{\mathrm{s}}$, but GrindoSonic measurements aim at limiting that uncertainty.

Regarding the effect of the length of the sample, a comparison of Figs. 9 and 10; 11 and 12; and 13 and 14 reveals that the results are more scattered when the length is

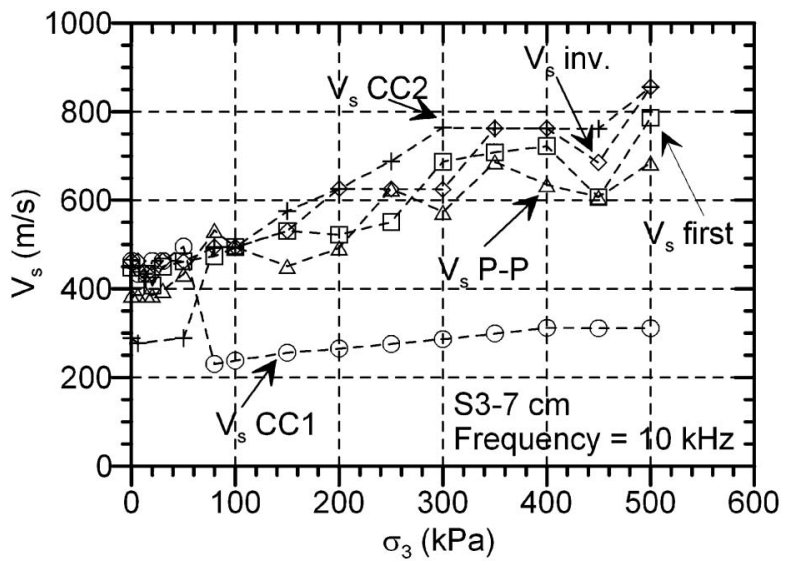

Fig. 13. Comparison of the different interpretation methods for the computation of shear waves velocities $(\mathrm{S3}-7 \mathrm{~cm}$ sample, $f=10$ $\left.\mathrm{kHz}, w=11 \%, u_{\mathrm{a}}-u_{\mathrm{w}}=60 \mathrm{kPa}\right)$

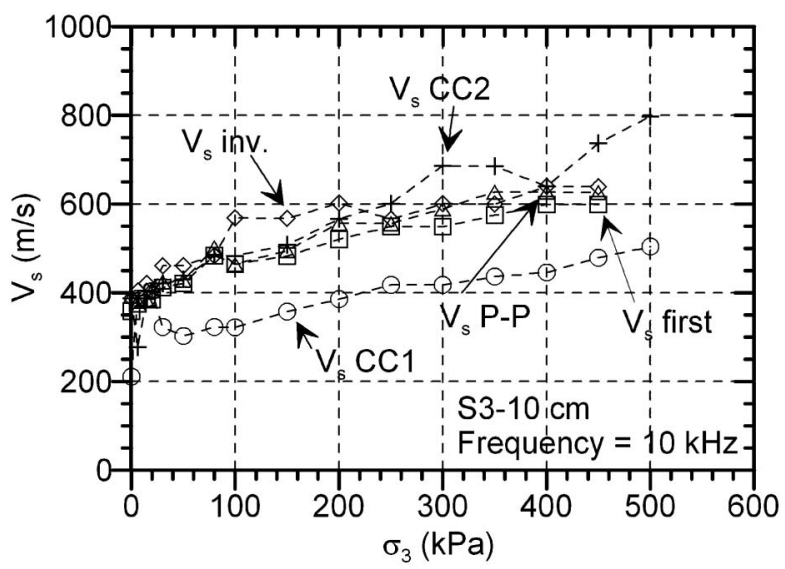

Fig. 14. Comparison of the different interpretation methods for the computation of shear waves velocities $(S 3-10 \mathrm{~cm}$ sample, $f=10$ $\left.\mathrm{kHz}, w=11 \%, u_{\mathrm{a}}-u_{\mathrm{w}}=60 \mathrm{kPa}\right)$

shorter. On the other hand, the length affects the measurement of the shear wave velocity in different ways: for soil S1, a higher shear wave velocity was measured on 10 $\mathrm{cm}$ samples although for S3 soils the higher shear wave velocity corresponded to $7 \mathrm{~cm}$ samples. There is no clear explanation for such variability. We found that specimens were relatively homogeneous and the material reconstitution was relatively repeatable. Probably this difference is related to the problems of contact between the bender elements and samples (clearly it is more difficult to ensure a good contact in a cohesive sample than in a frictional sample), or anisotropy. Further research is needed to elucidate this point.

The velocities, determined as the mean values obtained from the inversion and the first arrival methods, are not affected by the frequency and the shape of the input signal. Figure 15 summarizes the evolution of the shear wave velocities as a function of the confining pressures for different soil samples at $10 \mathrm{kHz}$.

Even if the bending and torsion frequencies obtained from GrindoSonic tests (Table 2) are lower than $10 \mathrm{kHz}$, 


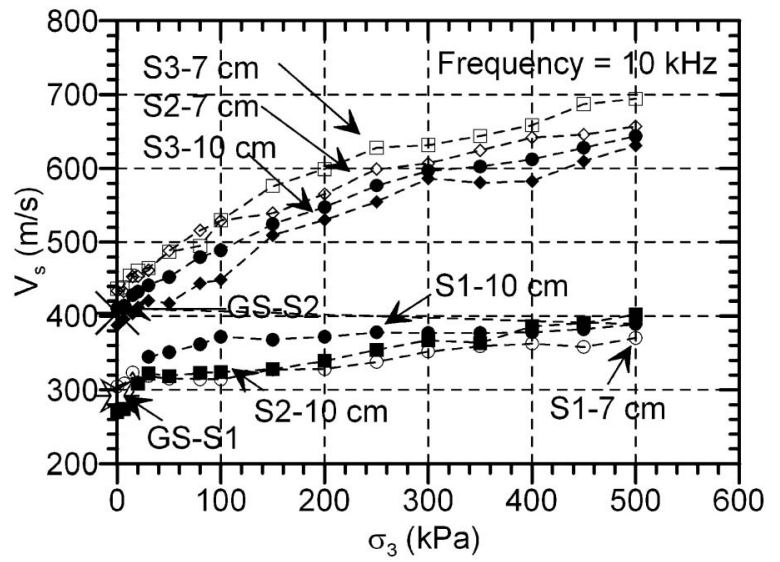

Fig. 15. Evolution of the shear wave velocities as a function of the confining pressures for all the soils at $10 \mathrm{kHz}$, and comparison with GrindoSonic measurements (GS)

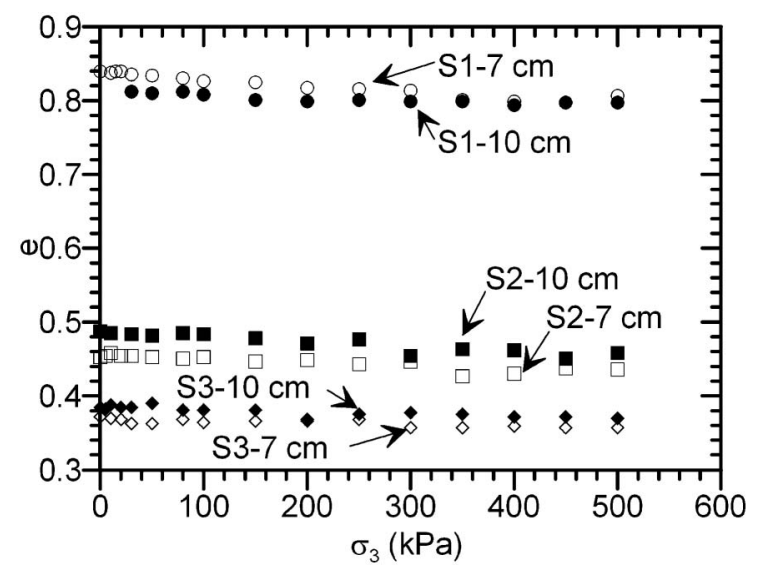

Fig. 16. Void ratio versus confining pressure

consistent values of shear wave velocities were obtained for soils $\mathrm{S} 1$ and $\mathrm{S} 2-7 \mathrm{~cm}$ (with a degree of saturation of $63 \%)$.

During isotropic compression, samples with a height of 7 and $10 \mathrm{~cm}$ for soils S1 and S3 showed similar void ratios and degrees of saturation (Figs. 15 and 16). As a result, the values of the shear wave velocities for the different heights are comparable. The range of shear wave velocities for soil $\mathrm{S} 1$ is between 300 and $400 \mathrm{~m} / \mathrm{s}$ and between 420 and $700 \mathrm{~m} / \mathrm{s}$ for soil S3, depending on the confining pressure. On the other hand, the two S2 samples show differences on $V_{\mathrm{S}}$ since these samples have been prepared with different initial saturation degrees (63 and 85\%), Fig. 17.

The two S2 samples prepared with different degrees of saturation $\left(S_{\mathrm{RS} 2 \mathrm{a}}=63 \%\right.$ for the $\mathrm{S} 2-7 \mathrm{~cm}$ and $S_{\mathrm{RS} 2 \mathrm{~b}}=85 \%$ for $\mathrm{S} 2-10 \mathrm{~cm}$ ) show shear wave velocities that vary between 280 and $400 \mathrm{~m} / \mathrm{s}$ (for a water content equal to $15 \%$ and a suction pressure of $300 \mathrm{kPa}$ ), and between 420 and $640 \mathrm{~m} / \mathrm{s}$ (for a water content equal to $11 \%$ and a suction pressure of $1500 \mathrm{kPa}$ ). The shear wave velocities obtained with the low saturated sample are $45 \%$ higher than the values obtained for the other sample (Fig. 15). Similar

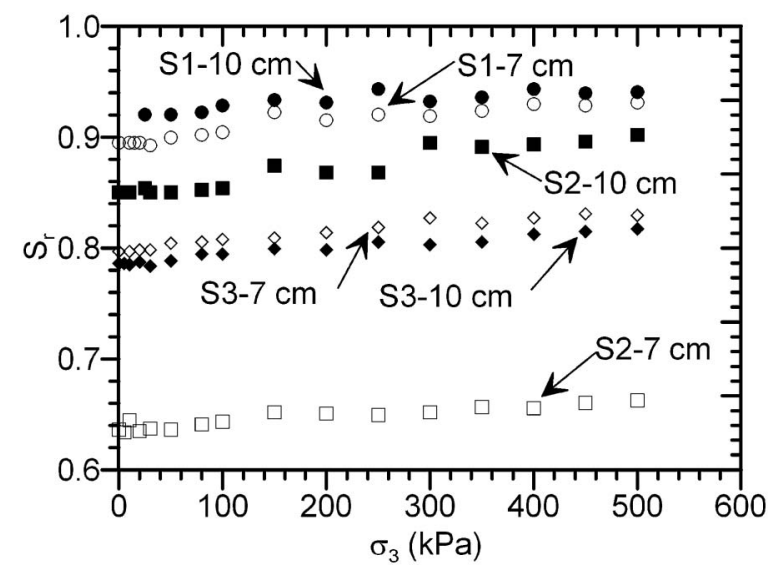

Fig. 17. Saturation degree versus confining pressure

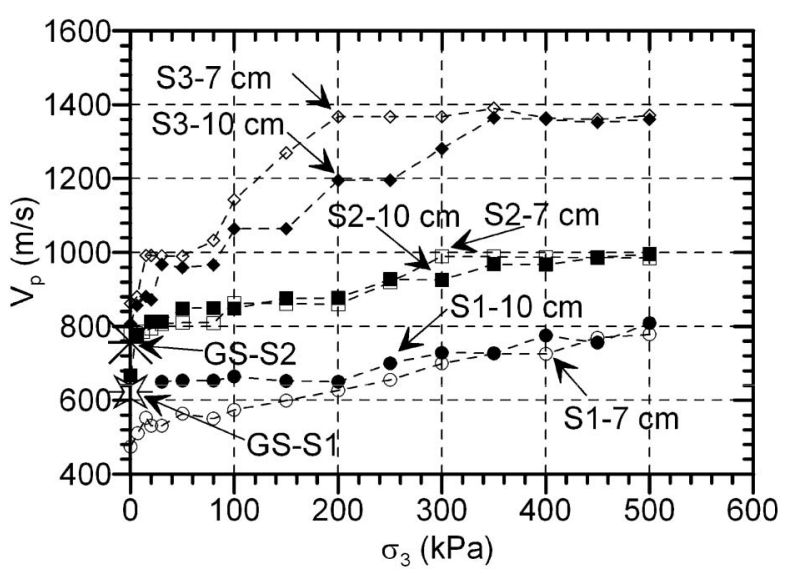

Fig. 18. Evolution of the compression wave velocities versus the confining pressures for all the soils at $10 \mathrm{kHz}$, and comparison with GrindoSonic measurements (GS)

results were also observed on granite and kaolin samples by Chun and Santamarina (2001). The measurements concerning the compression wave velocities show similar trends to the shear wave velocity (Fig. 18).

\section{EVOLUTION OF SHEAR AND YOUNG MODULI ALONG ISOTROPIC PATHS FOR UNSATURATED INTERMEDIATE SOILS}

A critical review of the literature shows that the shear and Young moduli of unbound granular materials mainly depends on the void ratio $e$ and on the effective principal stresses $\sigma_{1}^{\prime}$ and $\sigma_{3}^{\prime}$. For isotropic loading stress paths, the shear and Young moduli are expressed as a function of the void ratio and of the mean effective stress $p^{\prime}$ or the confining effective stress $\sigma_{3}^{\prime}$ such as (Hardin and Richart, 1963; Iwasaki and Tatsuoka, 1977; Biarez and Hicher, 1994; Lo Presti et al., 1997):

$$
\frac{G}{G_{\text {ref }}}=\frac{K_{\mathrm{G}}}{f_{\mathrm{G}}(e)}\left(\frac{\sigma_{3}^{\prime}}{\sigma_{3, \text { ref }}^{\prime}}\right)^{\mathrm{n}}
$$


Table 4. Relations between $G, E, e$ and $\sigma_{3}^{\prime}$

\begin{tabular}{l|c|c|c|c}
\hline \multicolumn{1}{c|}{ Reference } & Modulus & $\mathrm{n}$ & $f(e)$ & $\begin{array}{c}\text { Com- } \\
\text { ments }\end{array}$ \\
\hline Hardin \& Richart (1963) & $\mathrm{G}$ & 0.5 & $(2.17-e)^{2} /(1+e)$ & $\begin{array}{l}\text { Rounded } \\
\text { grains }\end{array}$ \\
\cline { 3 - 5 } Iwasaki \& Tatsuoka (1977) & $\mathrm{G}$ & 0.4 & $\mathrm{Cu}<1.8$ \\
\hline Biarez \& Hicher (1994) & $\mathrm{G}, \mathrm{E}$ & 0.5 & $1 / e$ & All soils \\
\hline Lo Presti et al. (1997) & $\mathrm{G}$ & 0.45 & $1 / e^{1.3}$ & Sands \\
\hline
\end{tabular}

$$
\frac{E}{E_{\text {ref }}}=\frac{K_{\mathrm{E}}}{f_{\mathrm{E}}(e)}\left(\frac{\sigma_{3}^{\prime}}{\sigma_{3, \text { ref }}^{\prime}}\right)^{\mathrm{n}}
$$

where $K_{\mathrm{E}}, K_{\mathrm{G}}$ and n are material constants, $f_{\mathrm{G}, \mathrm{E}}(e)$ a function of the void ratio (Table 4$)$ and $G_{\text {ref }}, E_{\text {ref }}, \sigma_{3, \text { ref }}^{\prime}(1 \mathrm{kPa}$ for instance) parameters that normalizes the equations. As observed, the power $n$ reported in literature, which characterizes the nature of grain-to-grain contacts, is close to 0.5 . The deviation from the predictions of the Hertz's theory $(n=1 / 3)$ can be explained by the nature of the contacts, which are not necessarily punctual (Dano and Hicher, 2002). For cohesive and frictional soils, the cementation of particles also makes the power $n$ decrease, down to 0 if the cementation is strong.

For the intermediate unsaturated materials used in this study, the variation of Young and shear moduli as a function of the confining stress depends on the sand fraction (or clay content) and on the suction as follows: (i) the higher the percentage of sand, the higher the shear and compression wave velocities are (Figs. 15 and 18). Furthermore, sandy soils are more pressure sensitive than pure clay: indeed, when a binder like clay or cement-type materials is added to the granular skeleton, the contact area between the grains increases and the effect of the pressure is softened (Chang and Woods, 1987); (ii) On the other hand, it is well-known that matrix suction has an effect on the shear wave velocity (Wu et al., 1984), even in the drying-wetting process (Xu et al., 2008).

GrindoSonic tests allow for the measuring the shear compression wave velocities for zero confining stresses (Figs. 15 and 18). The shear and Young moduli derived from these measurements reveal that for unsaturated intermediate materials, there are non-null moduli for zero confining stress. This effect is related to the capillary forces present in these materials. However, this result is in disagreement with Eqs. (6) and (7) for which zero moduli are expected for zero confining stress. To reproduce the effect of suction, Eqs. (6) and (7) could be modified in two ways: (i) using a generalized effective stress analysis (Fleureau et al., 2003), or (ii) by considering the suction effect on the modulus at zero stress and the effect of confining net stress separately (Caicedo et al., 2009). The second approach is used in this paper due to the difficulties in the definition of effective stresses in unsaturated soils. Then, to describe the variation of Young and shear moduli of intermediate unsaturated soils the following two power laws can be used:

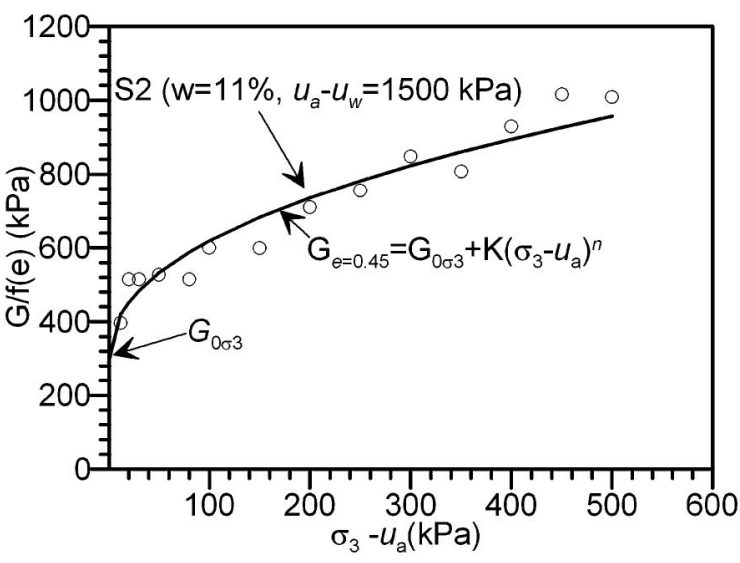

Fig. 19. Shear modulus vs net confining stress fitted using Eq. (8)

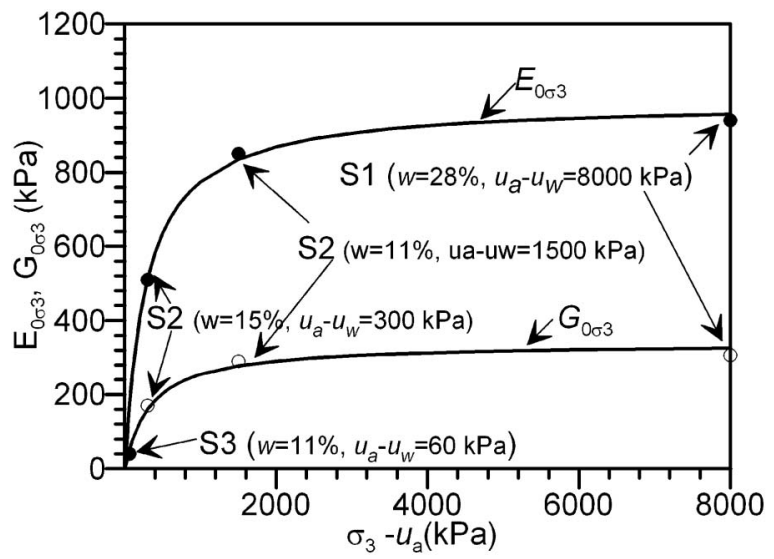

Fig. 20. Relationship between the modulus $E_{0 \sigma 3}, G_{0 \sigma 3}$, and suction

$$
\begin{aligned}
& \frac{G}{G_{\text {ref }}} f_{\mathrm{G}}(e)=\frac{G_{0 \sigma_{3}}}{G_{0 \sigma_{3, \text { ret }}}}+K_{\mathrm{G}}\left(\frac{\sigma_{3}}{\sigma_{3, \text { ref }}}\right)^{\mathrm{n}} \\
& \frac{E}{E_{\text {ref }}} f_{\mathrm{E}}(e)=\frac{E_{0 \sigma_{3}}}{E_{0 \sigma_{3, \text { ref }}}}+K_{\mathrm{E}}\left(\frac{\sigma_{3}}{\sigma_{3, \text { ref }}}\right)^{\mathrm{n}}
\end{aligned}
$$

Figure 20 shows the Young and shear moduli for zero confining vertical stress, $E_{0 \sigma 3}, G_{0 \sigma 3}$ (normalized to $e=0.45$ using the equations suggested by Iwasaki and Tatsuoka (1977) for shear modulus and Biarez and Hicher (1994) for Young modulus) as a function of suction, $\left(u_{\mathrm{a}}-u_{\mathrm{w}}\right)$ for all the soils of this study. As described, the modulus for zero total stress goes up as the suction increases. In fact, for zero total stress, the stiffness of the material appears as a result of the capillary forces acting on the contacts between the granular particles. These results agree with the results presented by Fleureau et al. (2003), and Caicedo et al. (2009). Figure 19 shows that for zero suction, both the Young and shear moduli for zero confining stress go to zero; this value agrees with Eqs. (6) and (7). On the other hand, when suction increases, the modulus at zero confining stress trends to a maximum asymptotic value. This behaviour can be described using the following hyperbolic equations (Fig. 20): 
Table 5. Constants used in Eqs. (11) and (12)

\begin{tabular}{|c|c|c|c|c|c|c|c|c|c|c|}
\hline \multirow{2}{*}{ Soil } & \multicolumn{5}{|c|}{ Shear modulus $\mathrm{kPa}$} & \multicolumn{5}{|c|}{ Young Modulus kPa } \\
\hline & $a_{\mathrm{G}}$ & $b_{\mathrm{G}}$ & $f(e)$ & $K_{\mathrm{G}}$ & $n$ & $a_{\mathrm{E}}$ & $b_{\mathrm{E}}$ & $f(e)$ & $K_{\mathrm{E}}$ & $n$ \\
\hline S1 & \multirow{4}{*}{0.99} & \multirow{4}{*}{$3 \times 10^{-3}$} & \multirow{4}{*}{$(2.17-e)^{2} /(1+e)$} & 8.3 & 0.48 & \multirow{4}{*}{0.28} & \multirow{4}{*}{$1 \times 10^{-3}$} & \multirow{4}{*}{$1 / e$} & 38.3 & 0.48 \\
\hline $\mathrm{S} 2(\mathrm{w}=11 \%)$ & & & & 43.3 & 0.43 & & & & 79.9 & 0.46 \\
\hline $\mathrm{S} 2(\mathrm{w}=15 \%)$ & & & & 7.0 & 0.49 & & & & 18.5 & 0.48 \\
\hline $\mathrm{S} 3$ & & & & 55.07 & 0.49 & & & & 180.8 & 0.48 \\
\hline
\end{tabular}

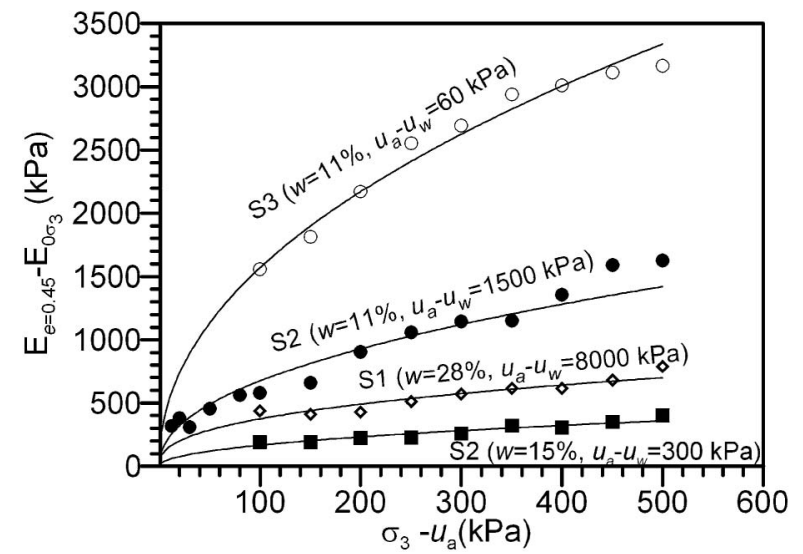

Fig. 21. Relationship between the component $E_{\mathrm{e}}=0.45-E_{0 \sigma 3}$ of Young modulus vs confining net stress $\sigma_{3}-u_{\mathrm{a}}$

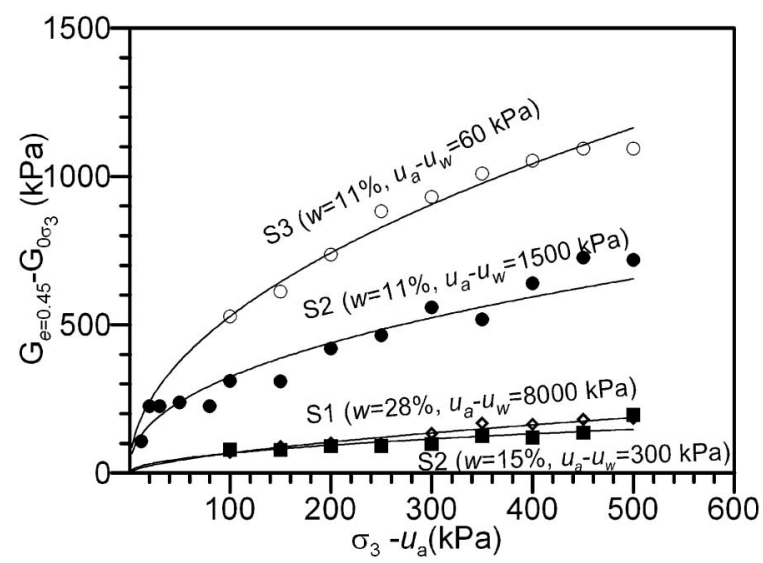

Fig. 22. Relationship between the component $G_{\mathrm{e}}=0.45-G_{0 \sigma 3}$ of shear modulus vs confining net stress $\sigma_{3}-u_{\mathrm{a}}$

$$
G_{0 \sigma_{3}}=\frac{u_{\mathrm{a}}-u_{\mathrm{w}}}{a_{\mathrm{G}}+b_{\mathrm{G}}\left(u_{\mathrm{a}}-u_{\mathrm{w}}\right)}, E_{0 \sigma_{3}}=\frac{u_{\mathrm{a}}-u_{\mathrm{w}}}{a_{\mathrm{E}}+b_{\mathrm{E}}\left(u_{\mathrm{a}}-u_{\mathrm{w}}\right)} \quad(10 \mathrm{a}, 1
$$

Figure 20 shows that using the previous equations, the Young and shear moduli of the intermediate soils used in this study can be described using the same equation. Particularly, the similar behaviour against the suction of soils S2 and S1 could be explained because both soils have fine fraction prepared with the same soil (kaolin SPW).

Figures 21 and 22 show the evolution of the component of shear and Young modulus that vary with the confining net stress, $\left(E_{\mathrm{e}}=0.45-E_{0 \sigma 3}\right.$, and $G_{\mathrm{e}}=0.45-G_{0 \sigma 3}$ vs.

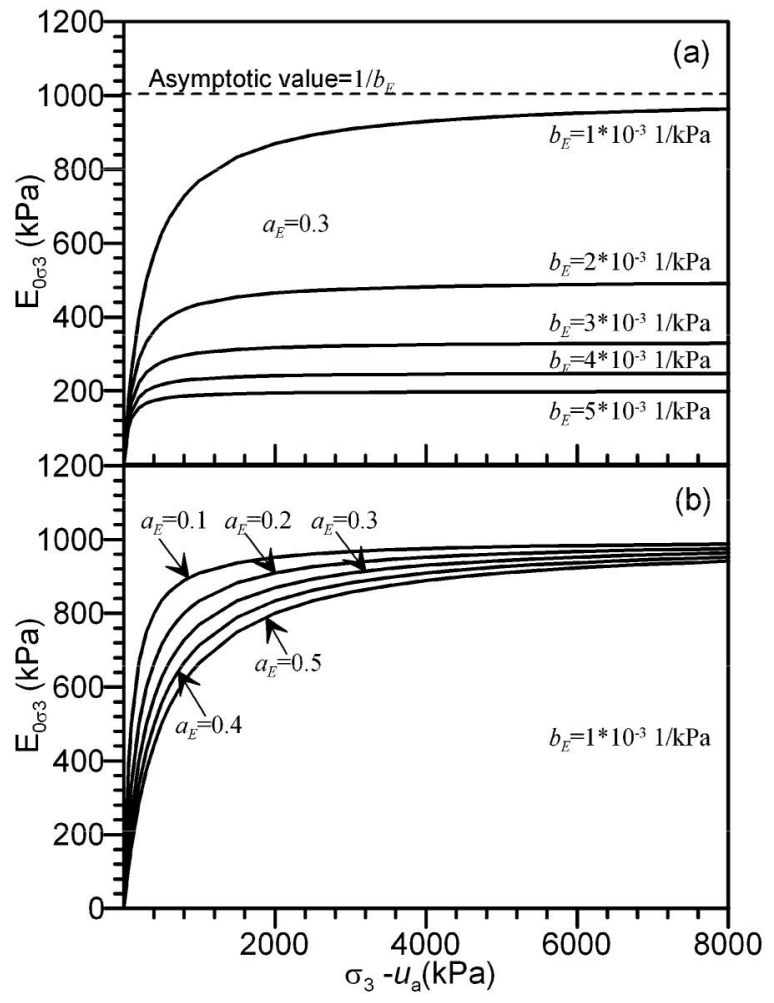

Fig. 23. Curves of modulus $E_{0 \sigma 3}$ upon matric suction for different values of $a_{\mathrm{E}}$ and $b_{\mathrm{E}}$

$\sigma_{3}-u_{\mathrm{a}}$ ). Table 5 shows the values of the constants used to fit the experimental results in to Eqs. (10), (11) and (12). The results of the exponent $n$ vary between 0.43 and 0.49 for all the soils of this study, and for either Young or shear moduli; these values are similar to those presented in Table 4 corresponding to saturated unbound soils. This last result confirms that Eqs. (6) and (7) can be used for intermediate unsaturated soils but only to describe the effect of the net confining stress separately of the modulus for zero confining stress.

$$
\begin{aligned}
& G f_{\mathrm{G}}(e)=\frac{u_{\mathrm{a}}-u_{\mathrm{w}}}{a_{\mathrm{G}}+b_{\mathrm{G}}\left(u_{\mathrm{a}}-u_{\mathrm{w}}\right)}+K_{\mathrm{G}}\left(\sigma_{3}-u_{\mathrm{a}}\right)^{\mathrm{n}} \\
& E f_{\mathrm{E}}(e)=\frac{u_{\mathrm{a}}-u_{\mathrm{w}}}{a_{\mathrm{E}}+b_{\mathrm{E}}\left(u_{\mathrm{a}}-u_{\mathrm{w}}\right)}+K_{\mathrm{E}}\left(\sigma_{3}-u_{\mathrm{a}}\right)^{\mathrm{n}}
\end{aligned}
$$

As observed in Table 5, the exponent $n$ is similar for all the soils studied; however, the constant $K$ in Eqs. (11) and 


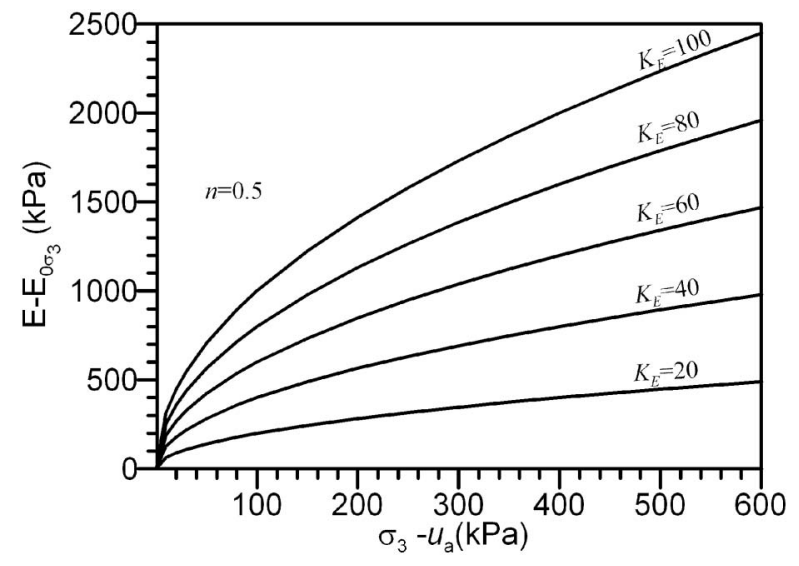

Fig. 24. Component of Young modulus $E-E_{0 \sigma 3}$ vs confining net stress for different values of $K_{\mathrm{E}}$ and $\boldsymbol{n}=\mathbf{0 . 5}$

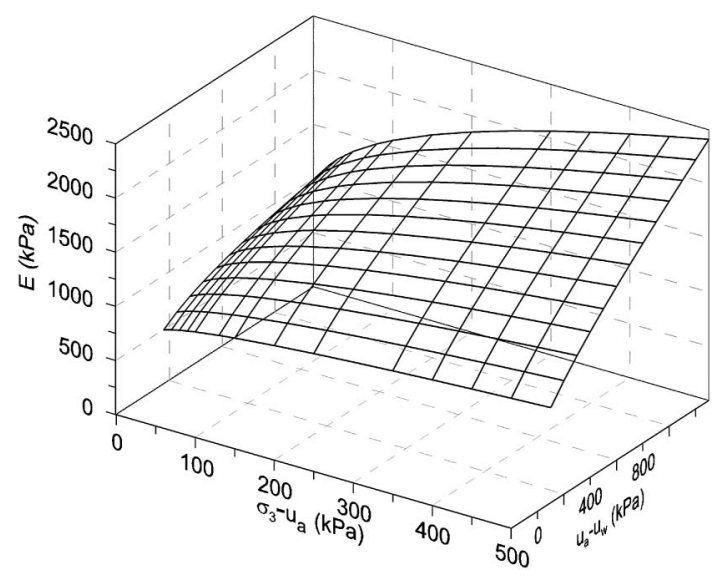

Fig. 25. Young modulus vs confining net stress $\sigma_{3}-u_{\mathrm{a}}$ and suction $u_{\mathrm{a}}$ $-u_{\mathrm{w}}$ for soil S2

(12) depends on the type of soil and suction value. Figures 23 and 24 give an empirical interpretation of Eqs. (11) and (12). Figure 23 shows how the parameters $a_{\mathrm{E}, \mathrm{G}}$ and $b_{\mathrm{E}, \mathrm{G}}$ work to incorporate the effects of matric suction in the shear and Young modulus at zero net stress: parameter $1 / b_{\mathrm{E}, \mathrm{G}}$ represents the asymptotic value of the curves relating the shear and Young modulus vs. matric suction (Fig. 23a); the shape of these curves is controlled by the parameter $a_{\mathrm{E}, \mathrm{G}}$ (Fig. 23b).

Figure 24 shows how $K_{\mathrm{E}, \mathrm{G}}$ works to describe the increase in the Young and shear modulus upon net stress. According to the results presented in this study, the parameter $K_{\mathrm{E}, \mathrm{G}}$ depends not only on the soil type but also on its matric suction. Further studies considering different suction values for the same soil are required to evaluate the variation of $K_{\mathrm{E}, \mathrm{G}}$ against suction. However, the variation of Young and shear modulus vs. suction and net confining stress for S2 soils can be obtained using Eqs. (11) and (12) considering a linear variation of $K_{\mathrm{E}, \mathrm{G}}$ vs. suction as a first approximation. Figures 25 and 26 show the evolution of Young and shear modulus vs suction and confining net stress. These figures show how Eqs. (11) and (12) describe the different growing rate of

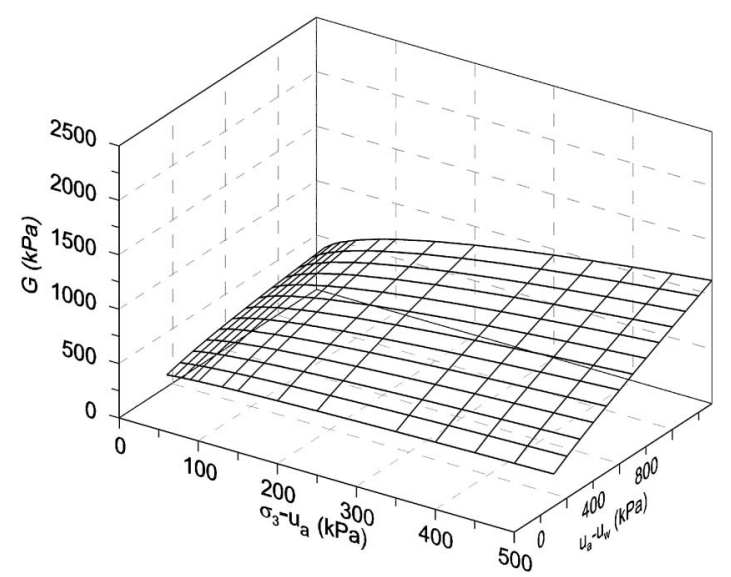

Fig. 26. Shear modulus vs confining net stress $\sigma_{3}-u_{\mathrm{a}}$ and suction $u_{\mathrm{a}}-$ $u_{\mathrm{w}}$ for soil $\mathrm{S} 2$

modulus when either the suction or the net confining stress remain constant.

\section{SUMMARY AND CONCLUSIONS}

Wave propagation velocities are experimentally determined for S1, S2 and S3 soils subjected to isotropic stresses. The statically reconstituted samples tested, which are both cohesive and frictional, are mixtures of kaolin SPW and Missillac sand, which represent a subgrade material.

The GrindoSonic test, based on the resonance frequency of the non-stressed sample, gives results for both the compression and shear wave velocities that are comparable with bender-extender element measurements.

The bender-extender element technique, which is not yet standardised, has been used for wave velocity identification in the framework of a parametric study that includes the effect of a) the length of the sample, b) the confining pressure, $c$ ) the nature of the soil, d) the frequency. This parametric study led to the following remarks concerning the use of bender element tests on intermediate compacted soils:

i. Even if near-field effects are systematically present, the effect of the length of the samples induce a discrepancy of lower than $15 \%$ on the wave velocities.

ii. As expected, both shear and compression wave velocities increase with the confining pressure. However, the shear wave velocities increased at a lower rate for confining pressures higher than 250 $\mathrm{kPa}$.

iii. Materials with a greater percentage of sand have higher shear wave velocity values.

iv. The test results show that a lower water content and higher suction pressure induces higher values for both the shear wave velocity and the Young's modulus values, for the same soil.

v. The range of frequency ( 5 to $10 \mathrm{kHz}$ ) gives consistent results, which are processed and interpreted using five different methods. In order to correctly get the shear wave velocity, the "inversion" and "first 
arrival" method are recommended. The peak-topeak method gives similar shear wave velocities for high excitation frequencies $(8.3,10 \mathrm{kHz})$; however, an overestimation of the propagation velocity is noted for lower frequencies.

vi. The results of the cross-correlation method are affected by the confining pressure and the input signal frequency. Nevertheless, the peak-to-peak, and the cross-correlation interpretations may be used as indicators.

The results of the Young's and shear moduli have been interpreted in the framework of unsaturated soils. For zero net confining stress, non null Young and shear moduli appear as a result of the suction pressure for all the soils which contradicts the power law used to describe the evolution of these modulus as a function of the confining stress. Due to the difficulties in the definition of the generalized effective stress law for unsaturated soils, two relations are proposed to describe the evolution of the Young's and shear modulus in compacted intermediate soils. With these laws, the Young's and shear modulus go up depending on the increase in suction and the increase in the confining net stress, separately. Using this description, the exponent of the power law for unsaturated soils fall within similar values to the exponent characteristic of the power law used for saturated soils in effective stress. It is acknowledged, however, that more tests are required to elucidate the variation of parameters $K_{\mathrm{G}}$ and $K_{\mathrm{E}}$ for different soils and conditions.

\section{ACKNOWLEDGEMENTS}

The authors would like to thank all colleagues who have contributed to the experiments. The funding for this work was partially supported by COLCIENCIAS, which is highly appreciated.

\section{REFERENCES}

1) Allison, R. J. (1988): A nondestructive method of determining rock strength, Earth Surface Processes and Landforms, Wiley, NewYork, 1-8.

2) Arulnathan, R., Boulanger, R. W. and Riemer, M. F. (1998): Analysis of bender element tests, Geotechnical Testing Journal, 21(2), $120-131$.

3) ASTM-D2845 Standard Test Method for Laboratory Determination of Pulse Velocities and Ultrasonic Elastic Constants of Rock, 8 .

4) Biarez, J. and Hicher P.-Y. (1994): Elementary Mechanics of Soil Behaviour-saturated and Remoulded Soils, Balkema.

5) Boulanger, R. W., Arulnathan, R., Harder, L. F., Torres, R. and Driller, M. (1998): Dynamic properties of Sherman Island peat, Journal of Geotechnical and Geoenviromental Engineering, ASCE, 124(1), 12-23.

6) Boussaid, K., Ferber, V., Garnier, J. and Thorel, L. (2003) Intermediate soils for physical modelling. International Symposium on Geotechnical Measurements and Modelling, Germany, 435-440.

7) Brignoli, E., Gotti, M. and Stokoe, K. H. (1996): Measurement of shear waves in laboratory specimens by means of piezoelectric transducers, Geotechnical Testing Journal, 19(4), 384-397.

8) Caicedo, B., Coronado, O., Fleureau, J. M. and Gomes Correia, A. (2009): Resilient behaviour of non-standard unbound granular materials, Int. J. Road Materials and Pavement Design, 10(2), 287-312.

9) Chang, T. S. and Woods, R. D. (1987): Effect of confining pressure on shear modulus of cemented sand. Developments in geotechnical engineering, Soil Structure Interaction, Elsevier, New York, 193-208.

10) Chun, C. and Santamarina, C. (2001): Unsaturated particulate materials particle level studies, Journal of Geotechnical and Environmental Engineering, 172(1), 84-96.

11) Dano, C. and Hicher, P. Y. (2002): Evolution of elastic shear modulus in granular materials along isotropic and deviatoric stress paths, Proc. 15th Engineering Mechanics Conference, ASCE, Columbia University, 6.

12) Dyvik, R. and Madshus, C. (1985): Laboratory measurement of $\mathrm{G}_{\max }$ using bender elements, Proc. Annual Convention, Advances in the Art of Testing Soils under Cyclic Conditions, ASCE, Detroit, 186-196.

13) Fam, M. and Santamarina, J. C. (1997): A study of consolidation using mechanical and electromagnetic waves, Géotechnique, 47(2), 203-219.

14) Fleureau, J.-M., Hadiwardoyo, S. and Gomes Correia, A. (2003): Generalised effective stress analysis of strength and small strains behaviour of a silty sand, from dry to saturated state, Soils and Foundations, 43(4), 21-33.

15) Foti, S. (2000): Multistation methods for geotechnical characterization using surface waves, $P h D$ thesis, Politecnico di Torino.

16) Fratta, D. and Santamarina, J. C. (1996): Waveguide device for multi-mode, wideband testing wave propagation in soils, Geotechnical Testing Journal, ASTM, 19(2), 130-140.

17) Hardin, B. O. and Richart, F. E. (1963): Elastic wave velocities in granular soils, Journal of the Geotechnical Engineering Division, ASCE, 89(1), 33-65.

18) ISO 13320-1 (1999): Particle Size Analysis-Laser Diffraction Methods-Part 1: General Principles.

19) Iwasaki, T. and Tatsuoka, F. (1977): Effects of grain size and grading on dynamic shear moduli of sands, Soils and Foundations, 17(3), 19-35.

20) Jovičić, V., Coop, M. and. Simic, M. (1996): Objective criteria for determining $\mathrm{G}_{\max }$ from bender element tests, Géotechnique, 46(2), 357-362.

21) Kawaguchi, T., Mitachi, T. and Shibuya, S. (2001): Evaluation of shear wave travel time in laboratory by bender element test, Proc. 15th Int. Conf. Soil Mechanics Foundations, Istanbul, 1, 155-158.

22) Kimura, J., Takemura, J., Hiro-oka, A. and Okamura, M. (1994): Mechanical behaviour of intermediate soils, Centrifuge 94, Balkema, Singapore, 13-24.

23) LCPC-Laboratoire Central des Ponts et Chaussées (1992): Réalisation des remblais et des couches de forme, France, Fascicules I $98 \mathrm{p}$ et II, 102 .

24) LCPC-Laboratoire Central des Ponts et Chaussées (2003): Practical manual for the use of soils and rocky materials in embankment construction, Guide technique. ISBN 2720831164, 60.

25) Leong, E. C., Yeo, S. H. and Rahardjo, H. (2005): Measuring shear wave velocity using bender elements, Geotechnical Testing Journal, ASTM, 28(5) 488-498.

26) Lings, M. L. and Greening, P. D. (2001): A novel bender/extender element for soil testing, Géotechnique, 51(8), 713-717.

27) Lo Presti, D. C. F., Jamiolkowski, M., Pallara, O., Pisciotta, V. and Ture, S. (1995): Stress dependence of sand stiffness, Proceedings of the 3rd International Conference on Recent Advances in Geotechnical Earthquake Engineering and Soil Dynamics, St Louis Missouri, 71-76.

28) Lo Presti, D. C. F., Jamiolkowski, M., Pallara, O., Cavallararo, A. and Pedroni, S. (1997): Shear modulus and damping of soils, Géotechnique, 47(3), 603-617.

29) Lohani, T. N., Imai, G. and Shibuya, S. T. (1999): Determination of shear wave velocity in bender element test, Proceedings of the second International Conference on Earthquake Geotechnical Engineering, Lisbon, 1, 101-106.

30) Mancuso, C., Simonelli, A. L. and Vinale, F. (1989): Numerical 
analysis of in situ S-wave measurements, Proc. of the 12th International Conference on Soil Mechanics and Foundation Engineering, Rio de Janeiro, 1, 277-280.

31) Mohsin, A. K. M. and Airey D. W. (2003): Automating $G_{\max }$ measurement in triaxial test. Deformation characteristics of geomaterials, Proceedings oh the 3nd International Symposium ISLyon, Balkema, Lyon, 73-80.

32) Murillo, C., Thorel, L. and Caicedo, B. (2009a): Spectral analysis of surface waves technique to evaluate the shear wave velocity in centrifuge models, J. Applied Geophysics, June, 68, 135-145. doi: 10.1016/j.jappgeo.2008.10.007.

33) Murillo, C., Caicedo, B. and Thorel, L. (2009b): A miniature falling weight for non destructive characterization of soils. Technical Note, Geot. Testing J., ASTM, 32(5), 465-474.

34) Rossato, G. Ninis, N. L. and Jardine, R. J. (1992): Properties of some kaolin based model clay soils, Geotechnical Testing Journal, 15(2), 166-179.

35) Sanchez-Salinero, I., Rosset, J. M. and Stokoe, K. H. (1986): Analytical studies of body wave propagation and attenuation, Civil Engineering Department University of Texas at Austin, GR86-15, Texas.

36) Scholey, G. K., Frost, J. D. and Jamiolkowski, M. (1995): A review of instrumentation for measuring small strains during triaxial test- ing of soils specimen, Geotechnical Testing Journal, 18(2), 137-156.

37) Sharifipour, M., Dano, C. and. Hicher, P.-Y. (2004): Wave velocities in assemblies of glass beads using bender-extender elements, 17th Engineering Mechanics Conference, ASCE, University of Delaware, Newark, CD-ROM.

38) Shirley, D. J. and Hampton, L. D. (1977): Shear wave measurements in laboratory sediments, J. Acoust. Soc. Am., 63(2), 607-613.

39) Spinner, S. and Tefft, W. E. (1961): A method for determining mechanical resonance frequencies and for calculating elastic moduli from these frequencies, American Society Testing Material Proc., 61, 1221-1238.

40) Viggiani, C. and Atkinson, J. H. (1995): Interpretation of bender element tests, Géotechnique, 45(1), 149-154.

41) Wu, S. Gray, D. H. and Richart, Jr. (1984): Capillary effects on dynamic modulus of sands and silts, J. Geotechnical Engineering, ASCE, 110(9), 1188-1203.

42) $\mathrm{Xu}, \mathrm{J} ., \mathrm{Ng}, \mathrm{C} . \mathrm{W}$. W. and Yung, S. Y. (2008): Drying and wetting effects on shear wave velocity of an unsaturated soil, Unsaturated Soils; Advances in Geo-engineering, (eds. by Toll et al.), Taylor and Francis, 525-530. 